\title{
REFORMA DA PREVIDÊNCIA: ARGUMENTOS E CONTRA-ARGUMENTOS QUE COMPETEM ENTRE SI NO DISCURSO
}

\author{
SANDRA GOMES RASQUEL ${ }^{1}$ \\ Programa de Pós-Graduação em Filologia e Língua Portuguesa \\ Universidade de São Paulo \\ Av. Professor Luciano Gualberto, 403. Cidade Universitária \\ 05508-900. São Paulo, SP, Brasil \\ sangr2012@yahoo.com.br
}

\begin{abstract}
Resumo. $O$ objetivo do presente trabalho é discutir as estratégias argumentativas presentes em notícia sobre a Reforma da Previdência, com a finalidade de compreender como o governo constrói argumentos para defendê-la e como contra-argumenta com os que são contrários. Utilizou-se como categoria de análise os conectivos discursivos argumentativos. Procedeu-se à análise qualitativa dos dados, sob o prisma das técnicas argumentativas de Perelman e Olbrechts-Tyteca, dos conectivos argumentativos por Ducrot e de conceitos da Análise Crítica do Discurso: contexto de Van Dijk e abuso de poder, em Wodak e Meyer e Van Dijk. Como resultados, prevaleceram no discurso a combinação de estratégias argumentativas e o fato de que a consideração do contexto pelo auditório parece enfraquecer os argumentos do orador.
\end{abstract}

Palavras-chave: estratégias discursivas-argumentativas; conectivos argumentativos; reforma da previdência; discurso político.

\begin{abstract}
The objective of the present paper is to discuss the argumentative strategies present in news about Social Security reform, in order to understand how the government constructs arguments to defend it and how it counter-argues with those who oppose it. Its category of analysis is the argumentative discursive connectives. The qualitative analysis of the data was carried out under the prism Perelman's and Olbrechts-Tyteca's argumentative techniques, the argumentative connectives by Ducrot and the concepts of Critical Discourse Analysis: Van Dijk's context and abuse of power in Wodak and Meyer and Van Dijk. As a result, the combination of argumentative strategies prevailed in the discourse, and the consideration of the context by the audience seems to weaken the speaker's arguments.
\end{abstract}

Keywords: discursive-argumentative strategies; argumentative connectives; reform of social security; political speech.

\footnotetext{
${ }^{1}$ Mestranda no Programa de Pós-Graduação em Filologia e Língua Portuguesa da Universidade de São Paulo.
} 


\section{INTRODUÇÃO}

A reforma da Previdência é um assunto polêmico que vem de anos e sua discussão se intensificou desde 2016, sendo uma das principais metas do presidente interino, Michel Temer (2016-2018). Longe de ser um consenso entre o governo, os parlamentares e estudiosos no assunto, o debate segue acirrado na mídia, com defesa de vários pontos e argumentações que se pautam em números, contas, formas de gestão, direitos e deveres do Estado, constituindo-se os polos a favor e contrários à reforma.

O objetivo do presente trabalho é discutir as estratégias argumentativas veiculadas na notícia "Deficit da Previdência daria uma dívida de $\mathrm{R} \$ 110$ mil para cada jovem brasileiro", publicada pelo Jornal OGLOBO por meio online, no dia 29/11/2017, tendose como finalidade compreender como o governo constrói argumentos para defender a reforma da Previdência e como contra-argumenta com os que são contrários a sua proposta, pelo viés da referida notícia. O estudo terá como categoria de análise os conectivos discursivos argumentativos, os quais contribuem para a construção da argumentação textual.

Para atender aos objetivos propostos neste trabalho, será feita a identificação, descrição e análise dos argumentos pró-reforma do corpus escolhido e dos contra-argumentos aos que são contrários à proposta de reforma, sob o prisma das técnicas argumentativas de Perelman e Olbrechts-Tyteca (2005 [1958]), das considerações de Ducrot sobre os conectivos argumentativos, além de alguns conceitos e discussões advindas da análise crítica do discurso, tais como: contexto de Van Dijk (2008); poder e abuso de poder, em Wodak e Meyer (2003) e Van Dijk (2012). Os conceitos escolhidos possibilitarão a compreensão do fato de um mesmo assunto/problemática gerar posições divergentes, atendendo a posições ideológicas e vivências de mundo. Será feita a análise qualitativa dos dados, discutindo-se as estratégias e os conectivos argumentativos que forem relevantes e prevaleceram no corpus.

A notícia sob análise corresponde ao documento fonte "Aspectos fiscais da seguridade social no Brasil", que foi elaborado pelo governo com a função de dar uma resposta aos que afirmam que a previdência não é deficitária. Foi desenvolvido para defender a proposta de reforma da previdência e para rebater os argumentos que são defendidos por entidades que afirmam que não existe o déficit na Seguridade Social, e portanto, julgam que a reforma não é necessária. Este documento foi divulgado no dia 29/11/2017 pelo Tesouro Nacional (2017), mesma data da notícia a ser analisada (BECK, 2017).

No caso do discurso político, veiculado nessa notícia, entende-se que há uma "comunicação estratégica", na medida em que, tal como defendido por Mafra (2008, p. 42), "a comunicação estratégica representa uma forma de construir e estabelecer processos comunicativos de forma planejada, e não espontânea". A notícia em análise tem como interesse argumentar a favor da reforma e conseguir a adesão dos que são contrários a essa proposta à ideia de que tal reforma se faz necessária.

$\mathrm{O}$ outro, a quem se quer influenciar, é considerado pela retórica como o auditório. $\mathrm{O}$ auditório, segundo a retórica, pode ser definido como o "conjunto daqueles que o orador quer influenciar com sua argumentação". Assim, a linguagem não é apenas um meio de 
comunicação, mas de ação sobre os espíritos, uma estratégia de persuasão (PERELMAN; OLBRECHTS-TYTECA, 2005 [1958], p. 22).

De acordo com Petri (2005), Perelman considera três tipos principais de auditório: o universal, que se refere à humanidade; o particular, com um só interlocutor ou um grupo com características e interesses comuns, e o constituído pelo próprio locutor, mediante seus monólogos interiores ou registros em diários pessoais. Então, no caso do corpus, podemos considerar o auditório como do tipo "particular", já que o público a se conquistar a adesão são, especificamente, os que acreditam que não há déficit no sistema previdenciário, e que, portanto, desaprovam a proposta de reforma, incluindo a população contrária à reforma e economistas e estudiosos no assunto, para os quais o documento do governo foi desenvolvido para contra argumentá-los. Esse auditório engloba diferentes classes sociais, com diferentes posicionamentos políticos, interesses e níveis de compreensão, assim, o orador precisa exercitar sua destreza para conseguir sua adesão. A adaptação do orador ao auditório é condição sine qua non para o sucesso de suas estratégias argumentativas. O discurso precisa estar adaptado a ele, e o que funciona em determinada situação pode não surtir o mesmo efeito e nem ser aceitável em outras (PERELMAN; OLBRECHTS-TYTECA, 2005 [1958]).

Assim, o documento do governo, ao usar a tese de que há déficit na Previdência, de que os gastos aumentam continuamente e estão se tornando insustentáveis, busca levar o auditório a uma conclusão específica, a da necessidade da reforma da Previdência.

Tal como coloca Petri (2005, p. 46), nas questões políticas "os valores intervêm como base da argumentação", a fim de levar o auditório a optar por uma determinada escolha, e "principalmente justificá-la, de forma a torná-la aceitável e aprovada pelos outros". Dado, então, os acordos iniciais entre o auditório e o orador, a argumentação caminhará no sentido de atingir sua finalidade, e para tal, técnicas argumentativas serão empregadas para facilitar a adesão dos espíritos.

De acordo com Perelman e Olbrechts-Tyteca (2005 [1958]), o discurso persuasivo produz efeito quando inserido em um todo, considerando-se todos os elementos discursivos em interação, posto que sua análise fora de contexto leva a equívocos e erros de interpretação.

Tal como posto por Amossy (2011, p. 133), a argumentação precisa ser analisada segundo o contexto em que se insere, considerando a situação concreta da enunciação: "quem fala a quem fala, em que relação de lugares"; o papel e o estatuto dos participantes e em quais circunstâncias de troca, considerando a fala situada "necessariamente, no quadro de um gênero de discurso que ocupa um lugar particular num espaço social dado e que comporta seus objetivos, suas regras e suas próprias restrições". Desse modo, ao analisar o discurso e os argumentos do orador, o auditório toma em conta o contexto.

Perelman e Olbrechts-Tyteca (2005 [1958], p. 16) esclarecem que "toda argumentação visa à adesão dos espíritos e, por isso mesmo, pressupõe a existência de um contato intelectual”. A argumentação direciona-se a um fim, busca a adesão do outro a determinadas ideias e ela pode se manifestar por meio da persuasão. Segundo Monteiro (2017, p. 195), a persuasão poderá ser alcançada "pelo caráter moral do orador, pelo efeito suscitado no auditório e pelo próprio discurso". 
Nos termos de Van Dijk (2012), o contexto, tão importante para a argumentação, significa a estrutura mental na qual se representam as situações sociais que são relevantes para produzir e compreender o discurso. Ele se constitui por categorias tais como: a situação geral do discurso; o cenário espaço-temporal; os gêneros discursivos; os participantes envolvidos em seu papel comunicativo, social ou institucional, bem como suas representações mentais, que incluem: as ideologias do grupo, suas opiniões pessoais, suas atitudes e conhecimentos.

Nesse cenário, tem-se de um lado o orador que argumenta em seu discurso, e do outro, a atitude do auditório frente ao discurso proferido, podendo contra-argumentar acerca do que ouve/lê. Desse modo, a argumentação caracteriza-se por uma interação constante entre todos os seus elementos, estando em jogo no ato de argumentar o que é verossímil, plausível e aceitável e não a verdade em si. Conforme Perelman e Olbrechts-Tyteca (2005 [1958], p. 214), "é levando em conta essa sobreposição de argumentos que se conseguirá explicar melhor o efeito prático, efetivo, da argumentação". Na interação entre o orador, o público e o discurso, deve haver um ambiente favorável à argumentação, e, para que ela se desenrole, o auditório deve ter sua atenção dirigida ao discurso.

O conhecimento do auditório faz parte da condição para que a argumentação seja eficaz. Um auditório heterogêneo exige do orador uma certa habilidade para argumentar, já que está diante de "grupos múltiplos" (PERELMAN; OLBRECHTS-TYTECA, 2005 [1958], p. 24-25). De acordo com Mauro (apud MOSCA, 2004), o conhecimento do auditório, de suas paixões, ideologias, valores e crenças são fundamentais para a escolha das premissas que sustentarão o direcionamento da argumentação.

Segundo Perelman e Olbrechts-Tyteca (2005 [1958]), as premissas podem ser consideradas como ponto de partida dos raciocínios que servirão de fundamento para a construção dos argumentos. Nesse sentido, o orador conta com a adesão do auditório a essas proposições iniciais.

Petri (2005, p. 109-110) cita os trabalhos da descrição semântica desenvolvidos por Ducrot, em que há na gramática da própria língua o reconhecimento de um "valor argumentativo ou retórico". A orientação argumentativa é determinada no próprio enunciado, orientando o discurso para certas conclusões, tais como é possibilitado pelos operadores ou conectivos argumentativos. As estratégias argumentativas utilizadas são favorecidas pelo próprio poder de persuasão do discurso, dado que os conectivos argumentativos exercem um direcionamento argumentativo que leva a conclusões específicas, conforme pretende o orador em seu ato comunicativo.

A autora ressalta que o "mas" é considerado por Ducrot como o "operador argumentativo por excelência", o qual imprime no enunciado uma única conclusão, mas duas orientações argumentativas que não convergem. Assim, a conclusão $r$ é sugerida por $p$ e não confirmada por $q$, em que a força contrária de $q$ é maior do que a força de $p$ a seu favor, levando-se a $\sim r$ como conclusão. Já o conectivo de concessão "embora" se aproxima do "mas" como marcador de oposição entre elementos semânticos explícitos ou implícitos. "A estratégia do mas é a de frustrar a expectativa criada, enquanto a do embora é manter essa expectativa (PETRI, 2005, p. 112). 
Desse modo, este trabalho tratará da combinação das estratégias argumentativas utilizadas no corpus, ressaltando o poder de direcionamento argumentativo dos conectivos.

\section{METODOLOGIA}

A análise qualitativa dos dados englobará a discussão das estratégias argumentativas próreforma e dos contra-argumentos encontrados no corpus, destacando-se os conectivos que contribuíram para a formação da argumentação, sob a ótica da notícia em análise. A discussão dos resultados priorizará os elementos mais relevantes encontrados.

Desse modo, será feita a apresentação teórica das técnicas argumentativas e dos conectivos, para se proceder, posteriormente, à análise propriamente dita.

\section{As Estratégias e os Conectivos argumentativos}

Souza et. al. (2016, p. 147-148) sintetizam as técnicas argumentativas de Perelman e Olbrechts-Tyteca, que se constroem por associação ou dissociação de noções. Por associação, se organizam em argumentos:

Quase-lógicos - buscam a eficácia persuasiva na lógica formal e na matemática, tendo-se como exemplos: a regra da justiça; a definição; o sacrifício; a comparação; a reciprocidade; a transitividade e a inclusão/ divisão entre parte e todo.

Baseados na estrutura do real - passam-se de certos elementos da "realidade para outro, por sucessão (causa e consequência) ou por coexistência (ligação entre realidades desiguais), tendo-se como exemplos os argumentos: de autoridade; a fortiori (escala de valores, relacionando pessoas a seus atos); de desperdício; pragmáticos (em vista de suas consequências, positivas ou negativas).

Fundamentam a estrutura do real, como exemplos: as generalizações; o raciocínio por analogia; os exemplos; a ilustração (busca a adesão a uma regra já aceita); o modelo e o antimodelo.

$\mathrm{Na}$ técnica por dissociação, os argumentos se organizam em prol de modificar a estrutura dos elementos isolados que deveriam ficar separados e independentes, tendo como função "fazer com que os fatos possam mudar de parecer ou finalidade" (SOUZA et. al., 2016, p. 148-149).

Os operadores e os conectivos argumentativos são recursos linguísticos impressos nos enunciados que servem como pistas para compreender como esses são processados, criam um sentido no texto e indicam uma direção argumentativa. Ainda que sejam usados, muitas vezes, como semelhantes, Lopes (1997), Rodríguez (2003) e Tordesillas (1993) esclarecem que há uma diferença entre eles. Os operadores atuam sobre um único enunciado e os conectivos articulam dois ou mais enunciados, que introduzem uma conclusão acerca do que foi pronunciado anteriormente. $\mathrm{O}$ operador argumentativo é aquele que pode ser compreendido independentemente do seu segmento enunciativo anterior, posto que seu escopo sintático e argumentativo se limita a um enunciado 
específico. Por sua vez, os conectores estabelecem, sintática e argumentativamente, uma relação com enunciados anteriores, articulando dois ou mais enunciados, que precisam ser tomados em conjunto para que haja uma compreensão do direcionamento argumentativo que está sendo construído.

Ambos ajudam no encadeamento dos enunciados e na coesão textual, além de direcionar a orientação do argumento, revelando as intenções do orador e seus interesses em busca da adesão do auditório. Tal como preconizado por Tordesillas (1993), a partir de certas partículas do enunciado, tais como os operadores ou conectivos argumentativos, podemos ter acesso ao: modo como o orador se posiciona diante do que comunica; à atitude que este quer impor ao auditório ao qual se dirige e à organização e direcionamento que imprime ao discurso. Um dos mecanismos que intervêm na configuração argumentativa é o uso dos conectivos, uma vez que eles estabelecem uma ligação dos distintos campos discursivos.

\section{RESULTADOS E DISCUSSÃO}

Uma das estratégias argumentativas presentes no corpus é o do tipo baseados na estrutura do real, argumento por autoridade, em que o governo e o documento fiscal elaborado por sua equipe, funcionam como argumentos para dar credibilidade ao que é defendido frente ao auditório. De acordo com Wodak e Meyer (2003, p. 30), a linguagem obtém seu poder a partir do uso que as "pessoas poderosas" fazem dela, podendo com isso influenciar outras pessoas.

Para os autores, a ACD se ocupa de analisar a produção da realidade que o discurso efetua, ao ser produzido e proferido pelas pessoas ativas, devendo-se ter atenção ao que é dito e a qual posição social o falante ocupa, já que o discurso será reflexo dos interesses, das intenções, das crenças e das ideias de quem o produz (WODAK; MEYER, 2003, p. 67).

Pronunciamentos e documentos do governo, como por exemplo, o documento do corpus em análise, tratarão de assuntos de seu interesse, promulgando as ideologias que circulam no meio político. Portanto, no discurso político, viabilizado por meio desse documento em defesa da reforma, a premissa caminha para que a existência do déficit seja atestada, orientando para a conclusão de que a reforma, tal como se configura na proposta do governo, é a saída necessária. Como o orador é representado pelo governo, o argumento de autoridade pode perder sua força, já que o auditório pode perceber os interesses políticos em jogo, que não convergem com seus interesses.

No corpus em análise, observamos que os argumentos predominantes para justificar a reforma da Previdência são feitos pela constante apresentação dos gastos de cada uma das fontes da Seguridade Social. Partindo-se, então, da premissa de que os gastos superam as receitas, o direcionamento argumentativo no corpus busca levar o leitor a aderir à tese de que: se os gastos superam os ganhos, há déficit, e se há déficit, há a necessidade de reforma. O uso da estratégia argumentativa por dados matemáticos e estatísticos é reforçado pelo uso de outras estratégias argumentativas do tipo argumentos baseados na estrutura do real, por sucessão, levando-se a constituir no discurso o vínculo entre causa e consequência entre os elementos, tal como visto em vários excertos do corpus: 
(1) O passivo previdenciário brasileiro é tão elevado que, se fosse distribuído entre a população mais jovem, cada pessoa carregaria hoje uma dívida superior R\$ 110 mil. O documento, intitulado "Aspectos fiscais da seguridade social no Brasil", destaca que o deficit atuarial do Regime Geral de Previdência Social (RGPS) e do Regime Próprio dos Servidores Civis da União (RPPS) soma R\$ 9,23 trilhões, ou 147\% do Produto Interno Bruto (PIB).

Nesta parte do excerto, ainda que se trabalhe no nível do irrealis, da suposição, o conteúdo é importante em termos da estratégia argumentativa utilizada, pois se constrói no discurso a ideia de que o déficit da Previdência é tão grande, que geraria uma grande dívida para cada jovem. Assim, supor a divisão da dívida com cada jovem e ter como escolha lexical o termo "carregaria" também funcionam como estratégias argumentativas que reforçam a ideia da gravidade da situação, fazendo a população sentir o "peso" da dívida. Assim, a relação entre os elementos tem como causa o passivo previdenciário e, como consequência, uma enorme dívida.

Outros excertos mostram a combinação dessas mesmas estratégias argumentativas, usadas para frisar o gasto constante e progressivo no Orçamento do Estado:

(2) $O$ texto destaca que, sem uma mudança no regime de aposentadorias no Brasil, esses gastos vão continuar consumindo parcelas cada vez maiores do Orçamento. O governo projeta que, sem reforma, apenas o deficit do RGPS subirá dos atuais $2,8 \%$ do PIB para 11,3\% do PIB em 2060, ou seja, 8,5 pontos percentuais.

(3) O estudo destaca que, considerando a Seguridade Social (que envolve não apenas a Previdência, mas despesas com saúde e assistência social), o rombo fica ainda maior. Ele foi de $\mathrm{R} \$ 239,5$ bilhões em 2016. Em 2007, o número era de R \$32,2 bilhões, o que significa que ele subiu $650 \%$ em nove anos. Os técnicos da equipe econômica apontam que esse aumento ocorreu devido a um descasamento entre $o$ crescimento das receitas e das despesas.

(4) De acordo com o documento, os gastos com pensões e reformas dos militares, por exemplo, apresentam descompasso "muito grande" com receitas. Enquanto a arrecadação desse grupo chega a $\mathrm{R} \$ 2,9$ bilhões, as despesas somam $\mathrm{R} \$ 37$ bilhões, o que resulta num deficit de R\$ 34,1 bilhões.

Em todos esses excertos têm-se argumentos baseados na estrutura do real, por sucessão, nos quais o argumento foi construído por causa e consequência, em que o "descasamento das despesas" é a causa do problema previdenciário e o déficit e o crescente "rombo" são as consequências. $\mathrm{O}$ argumento principal defendido é de que há déficit no sistema previdenciário, em que são apresentados dados que buscam "provar" sua existência e, assim, conseguir a adesão dos espíritos, para que se chegue à conclusão de que há necessidade de se fazer a reforma do sistema. Tal como preconizado por Fiorin (2015, p. 160-161), "os números dão uma aparência de objetividade à argumentação. No entanto, as cifras podem ser utilizadas segundo as necessidades da estratégia argumentativa empregada pelo enunciador". 
Prevalece no corpus o uso dos conectivos argumentativos conclusivos "assim"; dos conectivos adversativos "mas" e "no entanto"; dos conectivos aditivos "mas ainda" e dos concessivos "ainda assim" e "mesmo que".

No corpus, o uso do conectivo argumentativo conclusivo assim contribuiu para apresentar a tese de déficit no sistema, como nos excertos a seguir, além de outros usos que serão discutidos na sequência:

(5) Assim, o deficit do RGPS, incluindo o impacto desses incentivos, é de R\$ 138 bilhões.

(6) Assim, se esse montante fosse dividido igualmente entre crianças e jovens de até 25 anos - uma população de 83,7 milhões de pessoas cada uma delas pagaria $\mathrm{R} \$ 110.274$.

Outro uso estratégico do conectivo conclusivo assim, por toda a construção textual, foi para apresentar teses do que poderia ser feito para diminuir os gastos com o orçamento e se evitar uma reforma, mas logo a expectativa é frustrada com uma contra-argumentação, dada pelo próprio orador, que introduz um argumento de escala mais forte para propor a defesa de que a "única saída" que sobra, conclusivamente, é a reforma da Previdência, tal como se constata nos seguintes trechos:

(7) Assim, a saída seria aumentar a carga tributária ou cortar gastos em outras áreas importantes, como educação e segurança.

(8) Assim, segundo o estudo, para cobrir esse rombo será preciso aumentar a carga tributária nessa mesma proporção. O problema é que o peso dos impostos no bolso dos brasileiros, que já é elevado, saltaria de $20,9 \%$ para quase $30 \%$ do PIB na esfera federal, o que teria impacto negativo sobre a atividade econômica. Segundo o documento, haveria "redução da competitividade da produção brasileira nos mercados doméstico e internacional, aumento do incentivo à informalidade e evasão fiscal, entre outros".

(9) Assim, para compensar o aumento de custos com Previdência até 2060, seria preciso: dobrar a arrecadação da contribuição previdenciária; dobrar a do IR; triplicar a da Cofins; ou combinar as três medidas.

A função desses elementos linguísticos e dos contra-argumentos, usados nesses exemplos citados, funciona como jogo para direcionar e intensificar a argumentação principal defendida pelo orador, da necessidade de reforma, antecipando a resposta a possíveis argumentações de que essas outras medidas poderiam ser tomadas para se evitar a reforma.

Nesses mesmos excertos, a necessidade de reforma é justificada também para se evitar que outras medidas drásticas sejam tomadas, como o aumento de impostos ou a diminuição de gastos em despesas associadas às áreas da educação, segurança pública, dentre outras, o que denuncia o uso de outra estratégia argumentativa, o argumento quaselógico por associação do tipo sacrifício. 
Podemos compreender que, ao ser utilizado no discurso argumentos que levam a ameaçar outras esferas de interesse público, busca-se convencer o auditório de que a reforma da Previdência não só é necessária, como também permitirá defender interesses da população, como não aumentar a carga de impostos e não retirar direitos, como a educação e a saúde. De acordo com Barros (2013), a manipulação do outro pode ser feita ao se oferecer ganhos e/ou por intimidação e ameaça, tal como nesses exemplos do corpus.

Verificamos no corpus que os contra-argumentos referentes à não cobrança do sonegadores, às renúncias fiscais, à não inclusão dos militares e dos rurais na proposta de reforma, tem seus efeitos de prejuízo ao sistema minimizados pelo orador (governo), no entanto, são pontos fortemente atacados pelo auditório, que denunciam que a manutenção dessas medidas perpetuam o escoamento do dinheiro do sistema previdenciário e, portanto, são agravadores do problema e geradores do suposto déficit apresentado pelo governo, como veremos em textos que dialogam com o corpus em análise. $\mathrm{O}$ uso dos conectivos concessivos ainda assim e mesmo que; do conectivo adversativo no entanto e dos conectivos aditivos ainda e mas ainda funcionaram como elementos linguísticos que direcionaram as contra-argumentações, minimizando e buscando anular o benefício de se adotar outras medidas, que não a reforma, para sanar o suposto déficit, conforme os seguintes excertos:

(10) O trabalho rebate, ainda, os argumentos de que a Seguridade Social seria superavitária caso não existisse a DRU (Desvinculação de Receitas da União). Segundo o trabalho, o rombo seria menor, mas ainda existiria.

(11) "Se não houvesse aplicação da DRU no período de 2007 a 2016, ainda assim o resultado da Seguridade Social seria positivo apenas em 2007, apresentando déficits crescentes desde então.

(12) As renúncias fiscais, reconhece o texto, também têm impacto negativo sobre a Seguridade. No entanto, sua eliminação não seria suficiente para zerar o deficit. Pelas contas do governo, as renúncias tributárias com Previdência somaram R \$ 57,7 bilhões em 2016. (...) Já excluindo as renúncias da conta, o rombo cairia para cerca de $\mathrm{R} \$ 80$ bilhões. Ou seja, seria menor, mas ainda existiria.

(13) No longo prazo, percebe-se que, mesmo que essas renúncias fossem reduzidas a zero, o deficit da Previdência continuaria com a sua trajetória crescente, dado que elas tendem a se tornar cada vez menos significantes em relação ao deficit total”, afirma.

Segundo Bechara (2010, p. 331), o uso do conectivo aditivo mas ainda é usado como "conjunção enfatizada", criando no enunciado em análise o efeito de tentar anular a importância de se tomar essas outras medidas, no lugar de se fazer uma reforma. Essas contra-argumentações visam a enfraquecer a tese do auditório particular, já que, essencialmente, são dirigidos aos argumentos defendidos por ele para justificar a resolução da questão por outras vias. Tal como preconizado por Barros $(2013$, p. 74), na relação entre o sujeito político e o destinatário há um "jogo interacional de posições e atribuições de poder". 
O corpus em análise, em alguns trechos, retoma a posição dos que são contrários à proposta da reforma da previdência para contra argumentá-la. Podemos trazer textos circulantes na mídia que dialogam com o corpus para compreender melhor as estratégias argumentativas utilizadas. $\mathrm{Na}$ visão dos estudiosos no assunto que são contrários à proposta de reforma, a previdência é superavitária e, se há um suposto déficit, ele é criado pelo próprio governo, provocado pelas isenções, renúncias fiscais e pela DRU (desvinculação de valores), por vezes além dos 30\% permitido por lei, para ser usado para outros fins. "Ao não cobrar sonegadores e conceder renúncias fiscais, a União alimenta o problema que diz combater, avalia Denise Gentil, da UFRJ" (HAUBERT, 2017).

O economista e professor Eduardo Fagnani (UNICAMP) afirma: "O que está sendo apontado como déficit é a parte do governo, prevista no art. 195 da Constituição Federal que não é repassada para a Previdência" (CEE-FIOCRUZ, 2017). A tese de superávit é compartilhada também pelo relatório da CPI no Senado (PAIM et al., 2017) e em outros jornais da Mídia.

A denúncia desses fatos, pelo auditório, nas fontes já citadas, pode-nos levar à observação de uma outra estratégia argumentativa usada no discurso do governo, presente no corpus sob análise, que ocorre por dissociação de noções de par aparência/realidade, nos termos de Perelman e Olbrechts-Tyteca (2005 [1958]) e de essência/realidade em Fiorin (2015). Assim, o governo justifica a causa do déficit como sendo gerado pelos pagamentos aos aposentados e pelo gasto com a Seguridade Social, criando uma aparência do problema que ofusca e se contrapõe à verdadeira realidade, que inclui outras fontes de escoamento de verba, e que, se não igualmente resolvidas, perpetuarão esse cenário, do qual o governo reclama e, ao mesmo tempo, contribui para manter.

O orador (governo), ao responsabilizar a geração do déficit pelo pagamento das aposentadorias e pela recessão econômica e omitir dados, como as outras fontes que custeiam o sistema da Previdência, previstas na Constituição de 1988 (artigo 195), faz com que suas razões não sustentem suas conclusões, gerando um argumento falacioso.

O texto da economista Denise Gentil também comenta sobre as cinco fontes de arrecadação da previdência: COFINS; CPMF; CSLL; contribuição ao INSS (contribuição dos empregadores e dos trabalhadores à seguridade social) e a receita de concursos de prognósticos (loterias e apostas). Além dessas fontes, a Constituição prevê que "a seguridade social será financiada também pelos recursos do orçamento da União", entendendo-se que, portanto, o governo deve usar tais recursos para atender à demanda da seguridade social, somados às cinco fontes mencionadas (GENTIL, 2006, p. 34).

Essa manobra do governo, com a manipulação dos dados e de seus efeitos, por meio das estratégias argumentativas utilizadas para justificar o déficit, funcionam no corpus como abuso de poder, controle e manipulação ativada por meio da desinformação. O auditório, acionando estratégias cognitivas, como o seu conhecimento de mundo, para avaliação dos argumentos apresentados pelo governo, pode constatar a omissão de dados, levando ao enfraquecimento das teses do orador.

Para Van Dijk (2008, p. 17-18), o abuso de poder se dá no controle que se exerce sobre o outro, no qual prevalecem os interesses dos poderosos em contraposição aos interesses dos que são controlados, podendo tal controle ocorrer por meio do discurso e da influência 
de opiniões, atitudes e do conhecimento do outro. A argumentação no discurso é um recurso poderoso para se conseguir a adesão do outro. "Essa ação controlada pode de novo ser discursiva, de modo que o discurso poderoso possa, indiretamente, influenciar outros discursos que sejam compatíveis com o interesse daqueles que detém o poder".

Tal como posto por Charaudeau,

é, pois, a imbricação das condições extradiscursivas e das realizações intradiscursivas que produz sentido. Descrever sentido de discurso consiste, portanto, em proceder a uma correlação entre dois polos.

No âmbito da informação, isso equivale a se interrogar sobre a mecânica de construção do sentido, sobre a natureza do saber que é transmitido e sobre o efeito de verdade que pode produzir no receptor. (CHARAUDEAU, 2013, p. 40)

A análise do corpus nos permite perceber, ainda, que o auditório se afasta da conclusão do orador de que a reforma da Previdência é a única solução possível, por vislumbrar outras possibilidades, para as quais, o orador também contra-argumenta, como vimos anteriormente.

\section{CONCLUSÕES}

No corpus, os conectivos argumentativos, assim como a seleção lexical, foram recursos essenciais para o estabelecimento do poder persuasivo que se instaurou no discurso e contribuíram para a formação e o direcionamento argumentativo do texto.

Os resultados demonstraram que as estratégias argumentativas, geralmente, apareceram combinadas no discurso, convergindo para uma mesma conclusão, no caso do corpus estudado, buscar provar o déficit do sistema previdenciário. É importante notar que cada qual que se posiciona a favor ou contrário à proposta de reforma busca sustentar suas premissas e conclusões em sintonia com seus interesses, crenças, motivações, com seu papel social, bem como com a situação comunicativa em turno, carregadas de implícitos e jogos de poder.

Verificou-se que o auditório percebeu a disparidade entre o discurso argumentativo do governo, de justificar o déficit e sua prática de contribuir para que ele exista e se mantenha, denunciada nos textos que dialogam com o corpus em análise, o que parece enfraquecer a eficácia das estratégias argumentativas usadas pelo orador.

\section{REFERÊNCIAS}

AMOSSY, R. Argumentação e Análise do Discurso: perspectivas teóricas e recortes disciplinares. Trad. Bras. EID\&A, Revista Eletrônica de Estudos Integrados em Discurso e Argumentação, Ilhéus, n. 1, p. 129-144, nov. 2011.

BARROS, D.P. Política e Intolerância. Em: FULANETI, O.N.; BUENO, A.M. (Orgs.). Linguagem e Política 1: princípios teórico-discursivos. São Paulo: Contexto, 2013. p. 71-92.

BECHARA, E. Gramática Escolar da Língua Portuguesa. 2a ${ }^{a}$. ed. Rio de Janeiro: Nova Fronteira, 2010. 
BECK, M. Deficit da Previdência daria uma dívida de R\$ 110 mil para cada jovem brasileiro. O Globo, Rio de Janeiro, 29 jan. 2017. Disponível em https://oglobo.globo.com/economia/deficitda-previdencia-daria-uma-divida-de-110-mil-para-cada-jovem-brasileiro-22128994. Acesso em 11 jan. 2019.

BRASIL. Constituição (1988). Constituição da República Federativa do Brasil: texto constitucional promulgado em 5 de outubro de 1988, com as alterações determinadas pelas Emendas Constitucionais de Revisão nos 1 a 6/94, pelas Emendas Constitucionais nos 1/92 a 91/2016 e pelo Decreto Legislativo no 186/2008. Brasília: Senado Federal, Coordenação de Edições Técnicas, 2016. Disponível em https://www2.senado.leg.br/bdsf/bitstream/handle/id/518231/CF88 Livro EC91 2016.pdf. Acesso em 05 abr. 2019.

CEE-FIOCRUZ. O que está sendo apontado como deficit é a parte do governo, prevista no art. 195 da Constituição Federal que não é repassada para a Previdência, CartaCapital, São Paulo, 14 dez. 2017. Disponível em https://jornalggn.com.br/blog/cee-fiocruz/fagnani-contesta-estudodo-governo-que-afirma-que-jovens-terao-que-pagar-mais-impostos-para-zerar-deficit-da-pr.

Acesso em 19 jan. 2018.

CHARAUDEAU, P. Discurso das Mídias. Trad. Bras. 2a . ed. São Paulo: Contexto, 2013.

FIORIN, J.L. Argumentação. São Paulo: Contexto, 2015.

GENTIL, D.L. A Política Fiscal e a Falsa Crise da Seguridade Social. Análise financeira do período 1990 - 2005. Tese. Doutorado em Economia. Universidade Federal do Rio de Janeiro, Instituto de Economia, Rio de Janeiro, 2006.

HAUBERT, M. "É o próprio governo que provoca o déficit da Previdência", alerta economista, CartaCapital, São Paulo, 27 jan. 2017. Disponível em https://www.cartacapital.com.br/economia/e-o-proprio-governo-que-provoca-o-deficit-daprevidencia-alerta-economista. Acesso em 15 jan. 2018.

LOPES, A.C.M. Argumentação: uma área de investigação pluridisciplinar. Revista Portuguesa de Filologia, Universidade de Coimbra, 1997. Disponível em https://estudogeral.sib.uc.pt//handle/10316/47930. Acesso em 12 nov. 2018.

MAFRA, R. Entre o espetáculo, a festa e a argumentação: mídia, comunicação estratégica e mobilização social. Belo Horizonte: Autêntica, 2008.

MAURO, M.A.F. Argumentação e discurso. Em: MOSCA, L.S. (Org). Retóricas de ontem e de hoje. $3^{\text {a }}$. ed. São Paulo: Humanitas/FFLCH, 2004.

MONTEIRO, J.M. Os efeitos patêmitos em reportagens jornalísticas: argumentação e persuasão. Em: GOUVÊA, L.H.M. (Org.). Argumentação pela emoção - um caminho para persuadir. Rio de Janeiro: URFJ, $2017 . \quad$ Disponível em http://www.posvernaculas.letras.ufrj.br/images/Posvernaculas/Livros/Argumenta $\% \mathrm{C} 3 \% \mathrm{~A} 7 \% \mathrm{C} 3$ \%A30\%20Pela\%20Emo\%C3\%A7\%C3\%A30\%20um\%20caminho\%20para\%20persuadirmin.pdf. Acesso em 07 fev. 2020.

PAIM, P. et. al. Comissão parlamentar de inquérito da previdência social - CPIPREV. Brasília, 13 jul. 2017. Disponível em http://cpidaprevidenciaoficial.org/wpcontent/uploads/2017/07/Balan\%C3\%A7o-CPI-PREV.pdf. Acesso em 18 nov. 2018.

PERELMAN, C.; OLBRECHTS-TYTECA, L. Tratado da argumentação: a nova retórica. São Paulo: Martins Fontes, 2005 [1958].

PETRI, M. J. C. Argumentação linguística e discurso jurídico. $2^{\mathrm{a}}$. ed. São Paulo: Plêiade, 2005. RODRÍGUEZ, C.F. Operador/concetor, un criterio para la sintaxis discursiva. RILCE - Revista de Filologia Hispânica, v. 19, n. 1, 61-85, 2003.

SOUZA, G.S. de et. al. As técnicas argumentativas em diferentes esferas da comunicação: proposta de análise em textos jornalísticos, lítero-musicais, jurídicos e acadêmicos. REVEL, edição especial, v. 14, n. 12, 2016.

TESOURO NACIONAL. Aspectos Fiscais da Seguridade Social. Secretaria do Tesouro Nacional, 29 nov. 2017.2 Disponível em http://www.tesouro.fazenda.gov.br/documents/10180/0/Relat $\% \mathrm{C} 3 \% \mathrm{~B} 3$ rio + da + Previd $\% \mathrm{C} 3 \% \mathrm{AA}$

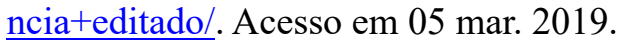


TORDESILLAS, M.I. Conectivos y operadores: una diferencia de dinámica argumentativa. Revista de Filologia Francesa, 3. Editorial Complutense, Madrid, 1993. Disponível em https://repositorio.uam.es/bitstream/handle/10486/676116/conectivos_tordesillas_tlm_1993.PD F? sequence=1. Acesso em 12 nov. 2018.

VAN DIJK, T.A. Discurso e contexto: uma abordagem sociocognitiva. São Paulo: Contexto, 2012.

VAN DIJK, T.A. Discurso e poder. São Paulo: Contexto, 2008.

WODAK, R.; MEYER, M. Métodos de análisis crítico del discurso. Barcelona: Gedisa, 2003.

\section{Anexo (Corpus de Análise)}

Deficit da Previdência daria uma dívida de R\$ 110 mil para cada jovem brasileiro Governo divulga documento para rebater argumentos contra reforma da Previdência por Martha Beck 29/11/2017 16:51/Atualizado 30/11/2017 8:34

BRASÍLIA - O passivo previdenciário brasileiro é tão elevado que, se fosse distribuído entre a população mais jovem, cada pessoa carregaria hoje uma dívida superior R\$ 110 mil. Isso é o que mostra estudo divulgado nesta quarta-feira pelo Ministério da Fazenda. O documento, intitulado "Aspectos fiscais da seguridade social no Brasil”, destaca que o déficit atuarial do Regime Geral de Previdência Social (RGPS) e do Regime Próprio dos Servidores Civis da União (RPPS) soma R \$ 9,23 trilhões, ou 147\% do Produto Interno Bruto (PIB). Assim, se esse montante fosse dividido igualmente entre crianças e jovens de até 25 anos - uma população de 83,7 milhões de pessoas - cada uma delas pagaria $\mathrm{R} \$ 110.274$. O déficit atuarial é quanto o governo precisa ter para pagar todos os benefícios previstos no futuro.

O documento foi preparado pelo governo para defender a aprovação da reforma da Previdência e rebater o argumento defendido por algumas entidades de que não existe déficit na Seguridade Social. O texto destaca que, sem uma mudança no regime de aposentadorias no Brasil, esses gastos vão continuar consumindo parcelas cada vez maiores do Orçamento. Assim, a saída seria aumentar a carga tributária ou cortar gastos em outras áreas importantes, como educação e segurança.

O governo projeta que, sem reforma, apenas o déficit do RGPS subirá dos atuais 2,8\% do PIB para $11,3 \%$ do PIB em 2060, ou seja, 8,5 pontos percentuais. Assim, segundo o estudo, para cobrir esse rombo será preciso aumentar a carga tributária nessa mesma proporção. O problema é que o peso dos impostos no bolso dos brasileiros, que já é elevado, saltaria de $20,9 \%$ para quase $30 \%$ do PIB na esfera federal, o que teria impacto negativo sobre a atividade econômica. Segundo o documento, haveria "redução da competitividade da produção brasileira nos mercados doméstico e internacional, aumento do incentivo à informalidade e evasão fiscal, entre outros".

\section{Descasamento entre receitas e despesas}

Pela forma como a carga tributária está distribuída hoje, a receita previdenciária é responsável por 5,7\% do PIB; o Imposto de Renda, por 5,4\%; a Cofins, por 3,3\%; o PIS/PASEP, por 0,9\%; e a Contribuição Social sobre Lucro Líquido (CSLL), por 1,1\%. Assim, para compensar o aumento de custos com Previdência até 2060, seria preciso: dobrar a arrecadação da contribuição previdenciária; dobrar a do IR; triplicar a da Cofins; ou combinar as três medidas. 
A outra solução possível seria reduzir despesas na mesma proporção do aumento do rombo, o que também teria impactos negativos. Haveria "redução de recursos para os demais programas de governo, associados a áreas como educação, segurança pública e investimento, entre outras".

O estudo destaca que, considerando a Seguridade Social (que envolve não apenas a Previdência, mas despesas com saúde e assistência social), o rombo fica ainda maior. Ele foi de R\$239,5 bilhões em 2016. Em 2007, o número era de R \$32,2 bilhões, o que significa que ele subiu $650 \%$ em nove anos. Os técnicos da equipe econômica apontam que esse aumento ocorreu devido a um descasamento entre o crescimento das receitas e das despesas. Enquanto o comportamento da arrecadação está diretamente relacionado à atividade econômica (que enfrentou uma recessão nos últimos anos), as despesas crescem com base no envelhecimento populacional, na valorização real do salário-mínimo e do piso para os benefícios sociais.

"O déficit se apresenta não só no resultado previdenciário, mas também nos componentes de saúde e assistência social. Trata-se de uma questão estrutural que precisa ser endereçada por uma reforma definitiva que garanta a sustentabilidade do sistema no médio e longo prazos, tendo em vista a impossibilidade de a sociedade brasileira sustentar o seu crescimento por meio de mais impostos", alerta o documento.

O trabalho rebate, ainda, os argumentos de que a Seguridade Social seria superavitária caso não existisse a DRU (Desvinculação de Receitas da União) - mecanismo que permite ao governo gastar livremente uma parte de suas receitas - sobre a Cofins nem renúncias fiscais sobre receitas da seguridade. Segundo o trabalho, o rombo seria menor, mas ainda existiria.

"Se não houvesse aplicação da DRU no período de 2007 a 2016, ainda assim o resultado da Seguridade Social seria positivo apenas em 2007, apresentando déficits crescentes desde então. Ou seja, têm sido necessários recursos do Orçamento Fiscal em montante superior às receitas desvinculadas para compensar os resultados negativos da Seguridade Social", destaca o documento.

As renúncias fiscais, reconhece o texto, também têm impacto negativo sobre a Seguridade. No entanto, sua eliminação não seria suficiente para zerar o déficit. Pelas contas do governo, as renúncias tributárias com Previdência somaram R \$ 57,7 bilhões em 2016. Assim, o déficit do RGPS, incluindo o impacto desses incentivos, é de R\$ 138 bilhões. Já excluindo as renúncias da conta, o rombo cairia para cerca de R $\$ 80$ bilhões. Ou seja, seria menor, mas ainda existiria. As renúncias decorrem da desoneração de folha de pagamentos, de benefícios a entidades filantrópicas, exportadores do setor rural, microempreendedores individuais e microempresas e empresas de pequeno porte que optaram pelo Simples Nacional.

\section{Militares: descompasso 'muito grande'}

No longo prazo, percebe-se que, mesmo que essas renúncias fossem reduzidas a zero, o déficit da Previdência continuaria com a sua trajetória crescente, dado que elas tendem a se tornar cada vez menos significantes em relação ao déficit total”, afirma.

O estudo divulgado pelo Ministério da Fazenda também deixa claro que duas das categorias de trabalhadores que o governo optou por deixar de fora da reforma da Previdência - militares e rurais — apresentam desequilíbrios significativos que também precisarão ser resolvidos futuramente.

De acordo com o documento, os gastos com pensões e reformas dos militares, por exemplo, apresentam descompasso "muito grande" com receitas. Enquanto a arrecadação 
desse grupo chega a $\mathrm{R} \$ 2,9$ bilhões, as despesas somam $\mathrm{R} \$ 37$ bilhões, o que resulta num déficit de $\mathrm{R} \$ 34,1$ bilhões.

Esse rombo, aponta o documento, é próximo ao observado pelo Regime Próprio dos Servidores Civis, de R \$ 43,1 bilhões, que possui um contingente muito maior. Comparado com o Regime Geral da Previdência Social (RGPS), o déficit dos militares também é elevado, especialmente considerando que o número de beneficiários civis e militares, que chega a um milhão, é 30 vezes menor que o de beneficiários do RGPS, de 29 milhões de pessoas.

No caso da Previdência rural, que acaba de ser retirada pelo governo da proposta de reforma das aposentadorias, o trabalho mostra que o déficit chega a R \$101,6 bilhões para 9,486 milhões de trabalhadores. Isso significa que o rombo per capita é de $\mathrm{R} \$ 10.715$. Na área urbana, por outro lado, esse valor é de $\mathrm{R} \$ 1.501$.

No caso dos servidores públicos, que têm um regime de aposentadorias mais favorável, mas foram incluídos na reforma, o déficit per capita é de $\mathrm{R} \$ 68.115$. No regime de aposentadorias para pensões militares, esse número é de $\mathrm{R} \$ 99.217$. Já no caso dos militares reformados, o rombo é de $\mathrm{R} \$ 127.692$.

Fonte: BECK, M. Déficit da Previdência daria uma dívida de R \$ 110 mil para cada jovem brasileiro. O Globo, Rio de Janeiro, 29 jan. 2017. Disponível em https://oglobo.globo.com/economia/deficit-da-previdencia-daria-uma-divida-de-110mil-para-cada-jovem-brasileiro-22128994. Acesso em 11 jan. 2019.

Artigo recebido em: abril de 2019.

Aprovado e revisado em: setembro de 2019.

Publicado em: dezembro de 2019.

Para citar este texto:

RASQUEL, SANDRA GOMES. Reforma da previdência: argumentos e contra-argumentos que competem entre si no discurso. Entremeios [Revista de Estudos do Discurso, ISSN 2179-3514, on-line, www.entremeios.inf.br], Seção Estudos, Programa de Pós-Graduação em Ciências da Linguagem (PPGCL), Universidade do Vale do Sapucaí (UNIVÁS), Pouso Alegre (MG), vol. 19, p. 35-49, jul. - dez. 2019.

DOI: http://dx.doi.org/10.20337/ISSN2179-3514revistaENTREMEIOSvol19pagina35a49 